\title{
Inaugural World Materials Summit to Be Held in October \\ www.euromaterialsforum.com
}

The inaugural World Materials Summit will be held in Lisbon, Portugal on October 4-5, 2007 as one of the events taking place during the Portugal's Presidency of the European Union and will be the opening event of a week of scientific meetings taking place in Portugal.

The event will open with specialists from the major industrialized countries involved in the problems of climate change giving a global perspective of the general policy adopted in their area of responsibility. The meeting will then focus mainly on the application of innovative materials for transportation and mobility, including the sources of energy and energy efficiency. Technology advances in transportation and mobility is seen as playing a major role in the efforts to miti- gate the emission of greenhouse gases contributing to global warming. These technical advances will involve the applications of materials science research.

The organizers of the conference plan to develop a coherent organization to achieve worldwide scientific and technological cooperation in materials science and technology to further develop the introduction of actions to slow the increasing rate of $\mathrm{CO}_{2}$ emissions. They intend for the conference to prepare, as a preliminary stage, an International Materials Roadmap to Combat Climate Change and to develop a fully materials objective scientific report to ensure that the materials science input to the world actions to combat climate change are fully exploited by the decision makers.
The Summit is a collaborative effort of the European Materials Forum (EMF), the European Materials Research Society (EMRS), the European Science Foundation (ESF), the Federation of European Materials Societies (FEMS), the European Technology Platform on Advanced Engineering Materials and Technologies (EuMaT), the Technology Platform on Zero Emission Fossil Fuel Power Plant (ZEP), the International Union of Materials Research Societies (IUMRS), and industrial sponsor Alstom.

Further information can be obtained from Web site www.euromaterialsforum.com.

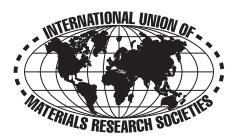

